\title{
A rare case of leiomyosarcoma arising from vault post-hysterectomy
}

\section{Sonal Bhuyar, Bhavana Sontakke, Neha Dharmale*}

Department of Obstetrics and Gynecology, Dr. PDMMC, Amravati, Maharashtra, India

Received: 27 October 2017

Accepted: 25 November 2017

\author{
*Correspondence: \\ Dr. Neha Dharmale, \\ E-mail: ndharmale@gmail.com
}

Copyright: (c) the author(s), publisher and licensee Medip Academy. This is an open-access article distributed under the terms of the Creative Commons Attribution Non-Commercial License, which permits unrestricted non-commercial use, distribution, and reproduction in any medium, provided the original work is properly cited.

\begin{abstract}
Fibroid/Leiomyoma is the most common benign tumor of the uterus, arising from uterine smooth muscle. Atypical leiomyomas are rare forms of Myoma (fibroid uterus), of which recurrent atypical leiomyoma post hysterectomy is rarer and its converting in leiomyosarcoma arising from vault is rarest. Here we report an unusual case of a 76yrs female, with leiomyosarcoma in an atypical leiomyoma arising from vault post-hysterectomy. A 76-year-old P3L3 patient presented with pain and distension of abdomen, post hysterectomy done 4 years back for chronic inversion and cervical fibroid polyp she was diagnosed as atypical leiomyoma. Laparotomy was done with a provisional diagnosis of leiomyosarcoma. Though Rarest $(0.13-0.26 \%$ ), a differential diagnosis of neoplastic changes should be kept in mind in patients with atypical leiomyoma, in patients presenting with any mass/pain abdomen, irrespective of any gynaecological complaints. This case shows that though it is unexpected after hysterectomy, leiomyosarcoma has to be considered in a case of abdominal mass. Atypical leiomyoma develops approximately in one to five cases out of 1,000 women with fibroid and it getting converted in leiomyosarcoma is rarest. Hence, diagnosis of leiomyosarcoma should always be kept in mind though the patient is hysterectomised.
\end{abstract}

Keywords: Atypical leiomyomyoma, Leiomyosarcoma

\section{INTRODUCTION}

Leiomyosarcoma is a malignant smooth muscle cell tumor of unknown origin. It is a smooth muscle cell tumor and is malignant. In appearance, it is fleshy, necrotic, haemorrhagic and fragile tissue. On histopathology, it has more than 7 mitotic figures in 10 high power field, 'bizarre' pattern and coagulative tumor cell necrosis.

\section{CASE REPORT}

76 years old female patient $\mathrm{P}_{3} \mathrm{~L}_{3}$ presented with following chief complaints of pain in abdomen and abdominal distention for 6 months and difficulty while micturition for 1 month. Patient had significant history of operative interference 4 times in past. 10 years back operated for cervical polyp. After 3 years, TAH with BSO was performed with a probable diagnosis of cervical cancer. Intraoperatively, a typical flower vase appearance of uterus with dimple present on fundus, both tubes and ovaries were pulled into the centre of dimple which was due to chronic inversion of uterus.

HPR was suggestive of atypical Leiomyoma. In 2015 i.e. after 4 years patient came twice in a gap of 6 months with vault polyp and polypectomy was performed twice. Again, HPR was suggestive of atypical Leiomyoma.

Keeping this previous history in mind, patient was investigated with routine preoperative profile. Ca125, CEA were normal and LDH was significantly raised. USG and CT scan showed huge heterogenic mass partly solid and cystic with necrotic areas of $20 \times 20 \mathrm{~cm}$ extending from symphysis pubis to xiphisternum suggestive of neoplastic origin. 
Patient was taken for exploratory laparotomy and debulking surgery with suspicion of malignancy. Intraoperatively, huge intraperitoneal neoplastic mass with plenty of bowel and omental adhesions seen. The mass removed piecemeal; weight $6.5 \mathrm{~kg}$. The mass was fleshy, bulging, necrotic and hemorrhagic (Figure 1).

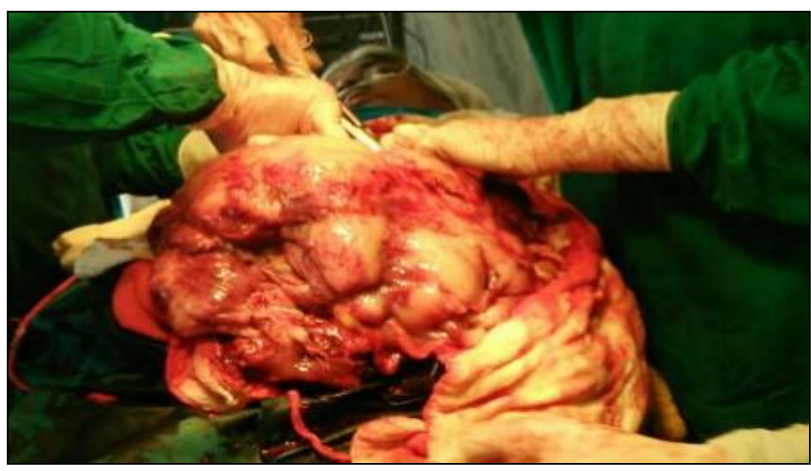

Figure 1: Intraoperative image showing fleshy appearance of tissue.

Histopathological report showed $>10 \mathrm{MF} / 10 \mathrm{HPF}$, focal 'bizarre' changes (Figure 2) and pleomorphic structures and mitotic figures (Figure 3). Diagnosis was confirmed as Leiomyosarcoma.

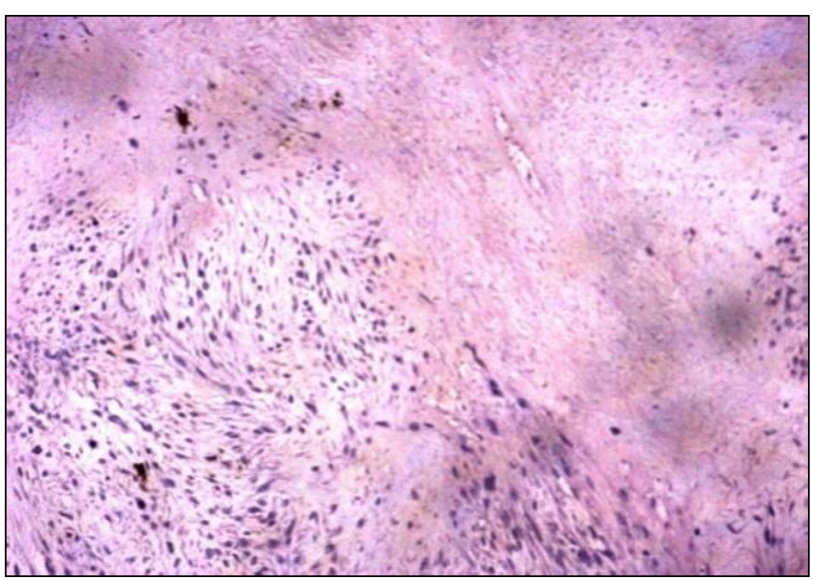

Figure 2: Slide showing bizarre changes.

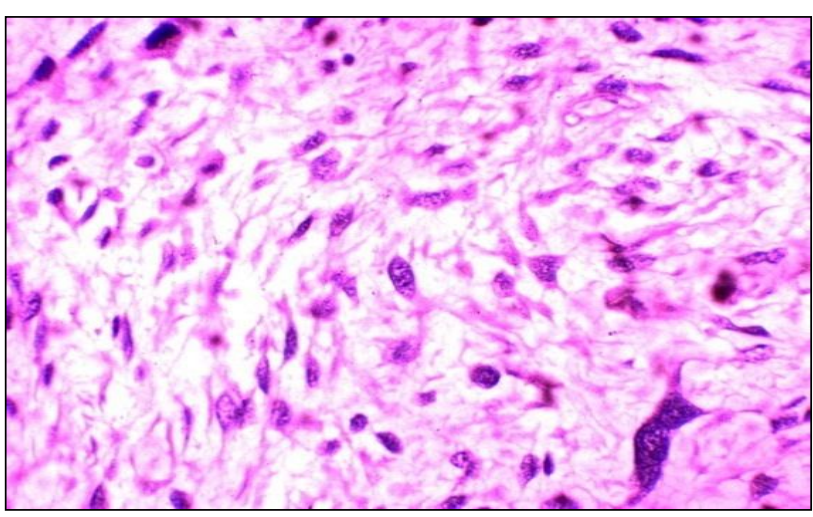

Figure 3: Slide showing pleomorphic structures and mitotic figures.

\section{DISCUSSION}

Leiomyosarcoma arising from vault post-hysterectomy in a case of recurrent atypical leiomyoma as we know is rare. This case meets the criteria for STUMP i.e. smooth muscle tumor of uncertain malignant potential in which due to lack of tumor necrosis and less than 10 mitotic figures per high power field these tumors are not labeled as malignant but have the potential to recur as a malignant one.

Leiomyosarcoma is a malignant smooth muscle cell tumor and is rare form of malignancy with poor prognosis. It accounts for $2-5 \%$ of all malignancies. ${ }^{1}$ Leiomyosarcoma are most common type of sarcomas accounting for $25-36 \%$ of uterine sarcomas. ${ }^{2,3}$ It is most commonly seen in involuntary muscles, uterus, stomach, intestine, retro peritoneum, walls of blood vessels and skin. Leiomyosarcoma have a primary site of origin anywhere in body where there is blood supply. Signs and symptoms consist of abdominal distention, pain in abdomen due to distention and postmenopausal pervaginal bleeding. ${ }^{4}$

Prognosis depends on extent of spread, age, histological type, tumor size, lymph node metastasis. ${ }^{5}$ Tumour more than $5 \mathrm{~cm}$ has poor prognosis. ${ }^{6}$ Metastasis occurs in the lung, brain, liver and bones. ${ }^{7}$

Mitotically active leiomyomas occur commonly in perimenopausal age group and have the typical macroscopic and histologic appearance of a leiomyoma. Leiomyomas which are hypercellular suggest the diagnosis of leiomyosarcoma. Atypical leiomyoma is considered as smooth muscle tumour of uncentain malignant potential (STUMP). This term was first used in the literature by Kempson in $1973 .{ }^{8}$

Imaging modalities like CT and MRI are not reliable diagnostic tools. ${ }^{9}$ Diagnosis of leiomyosarcoma is made microscopically.

On microscopy, coagulation tumor cell necrosis with hypercellularity and abundant mitosis i.e. $>10$ MF/10HPF, presence of aneuploidy, high MIB-1 activity and negative p53 and show focal 'bizarre' changes. It also shows atypia on cytology which is also a diagnostic tool.

Staging of leiomyosarcoma is surgical and local growth of leiomyosarcoma is its unique feature. Leiomyosarcoma extending beyond uterus and cervix has a poor prognosis.

Management consists of surgery, chemotherapy and radiotherapy. Neoadjuvant chemotherapy is used in advanced diseases. Single agent doxorubicin is effective for advanced cases. ${ }^{10}$ This case is unique because the atypical leiomyoma which have potential to undergo 
malignant changes was converted into leiomyosarcoma which is a very rare occurrence.

\section{CONCLUSION}

This case shows that though it is unexpected after hysterectomy, leiomyosarcoma has to be considered in a case of abdominal mass. Atypical leiomyoma developes approximately in one to five cases out of 1,000 women with leiomyomas and it is getting converted in leiomyosarcoma is rarest. Recent studies consist of phase II chemotherapy trails in advanced diseases.

Funding: No funding sources Conflict of interest: None declared

Ethical approval: Not required

\section{REFERENCES}

1. Forney JP, Buschbaum HJ. Classifying staging and treating uterine sarcomas. Contemporary $\mathrm{Ob}$ Gyn. 1981;18(3):47-69.

2. Norris HJ, Zalouder CJ. Mesenchymal tumour of uterus. In: Blaustein A, eds. Pathology of female genital tract. $2^{\text {nd }}$ edition. New York: Springer-Verlag Books; 1982:352-92.

3. Echt G, Jepson J, Steel J, Langholz B, Luxton G. Treatment of uterine sarcomas. Cancer. 1990;66:359.

4. Wickerham DL, Fisher B, Wolmark N, Bryant J, Costantino J, Bernstein L, et al. Association of tamoxifen and uterine sarcoma. J Clin Oncol. 2002;20:2758-60.

5. Major FJ, Blessing JA, Silverberg SG, Morrow CP, Creasmam WT, Currie JL, et al. Prognostic factors in early stage uterine sarcoma. A Gynaecologic Oncology group study. Cancer. 1993;71(4):1702-9.

6. Evans HL, Chawla SP, Simpson C, Finn KP. Smooth muscle neoplasms of the uterus other than ordinary leiomyoma. A study of 46 cases, with emphasis on diagnostic criteria and prognostic factors. Cancer. 1988;62(10):2239-47.

7. D'Angelo E, Prat J. Uterine sarcomas: a review. Gynecol Oncol. 2010;116:131-9.

8. Kempson RL. Sarcoma and related neoplasms. In: Norris HJ, Heritig AT, Abell MR, Eds. The uterus. Baltimore: Williams and Wilkins; 1973.

9. Pha SE, Byun JY, Jung SE. CT and MRI of uterine sarcoma and their mimickers. Am J Roentgenol. 2003;181:1369-74.

10. Piver MS, Lele SB, Marchetti DL, Emrich LJ. Effect of adjuvant chemotherapy on time to recurrence and survival of stage 1 uterine sarcomas. J Surg Oncol. 1988;38(4):233-9.

Cite this article as: Bhuyar S, Sontakke B, Dharmale N. A rare case of leiomyosarcoma arising from vault post-hysterectomy. Int J Reprod Contracept Obstet Gynecol 2018;7:349-51. 